EL MOTIVO DE LA ESPIRAL Y LOS MEANDROS EN PETROGRABADOS ASOCIADOS A OBRAS HIDRÁULICAS PRECOLOMBINAS DEL CARIBE DE COSTA RICA

MARCO ARCE CERDAS JEFFREY PEYTREQUINN GÓMEZ 


\section{EL MOTIVO DE LA ESPIRAL Y LOS MEANDROS EN PETROGRABADOS ASOCIADOS A OBRAS HIDRÁULICAS PRECOLOMBINAS DEL CARIBE COSTA RICA}

Revista Trama

Volumen 8, número 1

Enero - Junio 2019

Páginas 70-105

ISSN: 1659-343X

http://revistas.tec.ac.cr/trama
The Spiral And The Meanders Motives In Petroglyphs Associated To Pre-Columbian Hydraulic Architecture Of The Caribbean Costa Rica

Marco Arce Cerdas ${ }^{1}$ Jeffrey Peytrequín Gómez ${ }^{2}$

Fecha de recepción: 29 de septiembre de 2018 Fecha de aprobación: 12 de mayo de 2019

Arce, M., y Peytrequín, J (2019). El motivo de la espiral y los meandros en petrograbados asociados a obras hidráulicas precolombinas del Caribe Costa Rica. Trama, revista de ciencias sociales y humanidades, Volumen 8 , (1), págs. 70-105.

DOI: https://doi.org/10.18845/tramarcsh.v8i1.4461
1. Encargado del departamento de gestión de colecciones de la Fundación Museos del Banco Central de Costa Rica. San José, Costa Rica. Correo electrónico: arcemarcc@gmail.com , arcecm@bccr.fi.cr

2. Profesor asociado e investigador. Escuela de Antropología. Universidad de Costa Rica. San José, Costa Rica. Correo electrónico: odiseo@costarricense.cr 


\section{Resumen}

Este trabajo presenta una serie de resultados producto de investigaciones recientes efectuadas en el sitio arqueológico Rosa María (C-29 RM) y en el Monumento Nacional Guayabo (C-365 MNG), que ponen en evidencia un vínculo directo entre ciertas representaciones hechas sobre piedra (petrograbados) y algunas estructuras antiguas de carácter hidráulico. De tal forma, metodológicamente, se realiza un acercamiento a través de la recolección de datos en campo y el procesamiento espacial de los mismos que permiten efectuar la asociación de ciertos motivos y su ubicación en estas obras ingenieriles antiguas. Lo cual finalmente permite discutir y hacer interpretaciones concretas acerca de (1) el posible significado/ interpretación y (2) la funcionalidad de dichos grabados; esto de acuerdo a los datos directos obtenidos a partir del estudio de la arquitectura y el manejo de las aguas en el Caribe precolombino de Costa Rica.

Palabras clave: grabados pétreos, arquitectura hidráulica precolombina, Arqueología, Arte Rupestre, simbología.

\section{Abstract}

This paper presents the results of recent investigations carried out in the Rosa Maria archaeological site (C-29 RM) and in the Guayabo National Monument (C-365 MNG), which reveal a direct link between certain representations made on rocks (petroglyphs) and some ancient hydraulic structures. Thus, it provides a methodological approach based on field data recolection and its spatial analysis that enable to prove the association of certain motives and its location on those ancient engineering structures. With this in mind, the article discusses and establish context interpretations about (1) their possible meaning/interpretation and (2) the function of those engravings, this according to direct scientific data obtained product of the study of Pre-Columbian Costa Rica's water management practices and architecture.

Keywords: petroglyphs, Pre-Columbian hydraulic architecture, archaeology, Rock Art, Symbology. 


\section{INTRODUCCIÓN}

La interacción entre sociedades precolombinas y el agua es un problema complejo, que implica el análisis de distintas variables (culturales y ambientales), donde no solo se requiere considerar los aspectos formales de la obtención propiamente; sino, también, valorar las implicaciones en cuanto a la organización social y aspectos de cosmovisión.

Este trabajo aborda inicialmente la relación de algunas comunidades precolombinas del Caribe de Costa Rica con el agua; esto a través del estudio de las construcciones arquitectónicas vinculadas con la "gestión" de la misma. Así como, el vínculo de motivos de espirales y meandros ${ }^{3}$ grabados en las piedras que conforman estas estructuras o interactúan espacialmente con ellas.

La investigación se aborda desde una perspectiva donde se intenta sintetizar variada información recuperada y producida recientemente por los autores y otros investigadores.

Ya los autores han trabajado en una propuesta que generó y aclaró conceptos que permiten agrupar y depurar la clasificación de las distintas obras hidráulicas construidas durante la época precolombina en el Caribe de Costa Rica (Peytrequín y Arce, 2016). Inclusive, una versión preliminar de este trabajo fue presentada en el Primer Congreso Internacional "Centroamérica. Agua, Cultura y Territorio", efectuado en la Universidad Nacional de Costa Rica en el año 2017.

El actual escrito busca abordar un problema concreto, asociar una serie de resultados que ponen en evidencia un vínculo directo entre ciertas representaciones hechas sobre piedra (petrograbados), específicamente los motivos de espiral y meandros, con algunas estructuras antiguas de carácter hidráulico en lo que se conoce como el Caribe costarricense.

3. Representaciones de líneas onduladas, curvas o con proyecciones sinuosas; algunas de ellas simples y otras intricadas entre sí o conectadas con otros motivos. 
De tal forma, se realiza un acercamiento hacia (1) el posible significado/ interpretación de dichos motivos y (2) la funcionalidad asociada a esos grabados; esto de acuerdo a los datos directos obtenidos a partir del estudio de la arquitectura y el manejo de las aguas en la Costa Rica Precolombina; lo anterior, específicamente, en el sitio Rosa María (ubicado en Pacayitas de Turrialba) y en el Monumento Nacional Guayabo (localizado en Guayabo de Turrialba). 


\section{METODOLOGÍA}

La ruta trazada para la obtención de los datos de esta investigación implicó desarrollar una estrategia metodológica compuesta por varias etapas, a saber:

1- Etapa de Gabinete: Esta etapa consistió en el planeamiento y establecimiento de la investigación. Se fundamentó en la búsqueda de bibliografía específica sobre el tema abordado, la creación de la estrategia de recolección de los datos en campo, y la gestión de los permisos de los propietarios de los terrenos donde se ubican los sitios arqueológicos.

2- Levantamiento de datos en campo: Se efectuaron 10 giras a los sitios arqueológicos Rosa María y al Monumento Nacional Guayabo entre 2017 y 2019, con el objetivo de efectuar inspecciones meticulosas de las obras hidráulicas, registros de localización con GPS, un exhaustivo registro fotográfico; así como, el levantamiento de los motivos expuestos en los petrograbados por medio de su calco.

3- Procesamiento y análisis de la evidencia: Durante esta etapa, se desarrolló el redibujo digital de los calcos y el procesamiento de las imágenes fotográficas, se efectuaron mapas con el fin de observar tendencias en cuanto a los tipos de obras hidráulicas, la existencia o no de petrograbados en estas; así como la correlación de la presencia de los motivos de espiral y meandros en ciertas posiciones claves, conformando parte de la mampostería de dichas estructuras, todo esto a partir del cruce de las diferentes líneas de evidencia recabadas. 


\section{EL CARIBE ANTIGUO DE COSTA RICA Y EL AGUA}

Todos los sitios arqueológicos con obras hidráulicas, conocidos hasta ahora en el territorio nacional, se ubican en la Región climática Caribe Norte. El Caribe costarricense es una zona con una alta pluviosidad y esta vertiente no presenta una estación seca definida, pues las lluvias se mantienen entre los 100 y $200 \mathrm{~mm}$ en los meses menos lluviosos. Así, en esta zona existe un rango entre los 2500-4500 mm por año; con una precipitación promedio de $3300 \mathrm{~mm}$ anuales (Instituto Metereológico Nacional, 2016). A la vez, en el Caribe de Costa Rica no solo abunda el agua en forma de lluvia, sino que también presenta un recurso fluvial con una red hidrográfica compuesta por al menos 10 ríos de caudal importante.

\section{ANTECEDENTES SOBRE LAS OBRAS HIDRÁULICAS EN EL CARIBE DE COSTA RICA}

Respecto a los trabajos vinculados a obras hidráulicas precolombinas, en lo que hoy se conoce como el territorio costarricense (particularmente el Caribe), se debe señalar que estos son pocos $y$, los mismos, se han caracterizado (a nivel general) por no ser investigaciones a largo plazo ni relacionadas - de forma directa- a esta temática particular. Más bien, dichos acercamientos han sido esfuerzos aislados en el tiempo y producto de otros objetivos de investigación más amplios y que han dado cuenta, muchas veces de forma periférica, de la arquitectura antigua ligada al manejo de aguas (e. g. Fonseca, 1979; Vázquez, 2006 y Peytrequín, 2009; entre otros) ${ }^{4}$. 
Dentro de las investigaciones sí relacionadas -directamentecon obras hidráulicas precolombinas en nuestro país se pueden citar los trabajos desarrollados por Dubón, Solís y Fonseca (1984), Hernández (2007), Arce, Aguilar y Peytrequín (2015) y Peytrequín y Arce (2016). Es importante hacer notar que los autores de estas líneas tienen 4 años consecutivos acercándose a este tema; publicando ya un texto sintético (Peytrequín y Arce, 2016) con, por un lado, la información relativa a las obras hidráulicas precolombinas $y$, por el otro, una propuesta de clasificación de las mismas.

Con la finalidad de contextualizar la propuesta interpretativa de los petrograbados asociados a la arquitectura hidráulica precolombina, a continuación, se hará una breve síntesis de la clasificación de los tipos de obras hidráulicas. 


\section{SÍNTESIS DE CLASIFICACIÓN DE OBRAS HIDRÁULICAS PRECOLOMBINAS DEL CARIBE DE COSTA RICA}

En suma, se puede observar en el esquema siguiente la propuesta de clasificación (ver figura 1) con base en las características arquitectónicas propias de los sitios arqueológicos conocidos para Costa Rica y que muestran diferentes sistemas hidráulicos, entendidos estos últimos como el conjunto de estructuras, relacionadas entre sí, que permiten la conducción y el aprovechamiento del agua (Peytrequín y Arce, 2016).

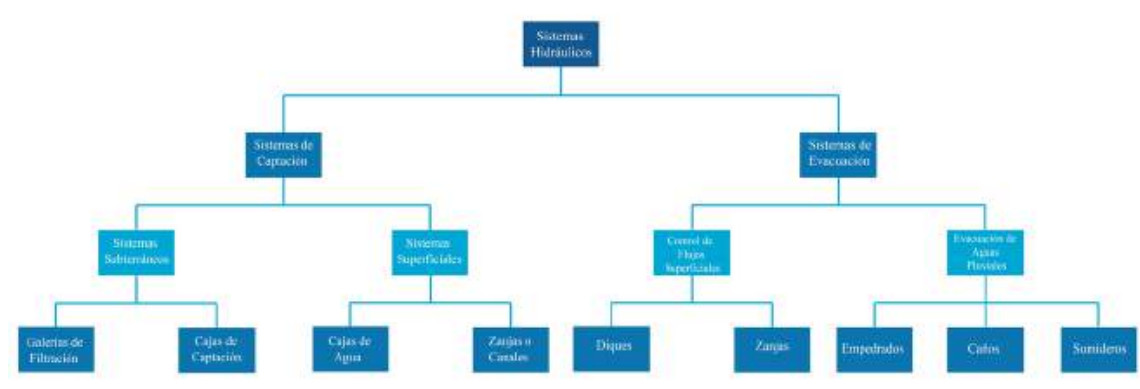

Figura 1. Esquema sintético de clasificación formal de las obras hidráulicas antiguas de Costa Rica

Los sitios con sistemas hidráulicos presentan tanto sistemas de captación como de evacuación de aguas, ya sea de manera individual o en conjunto (combinados). Los sistemas de captación los podemos definir como el conjunto de estructuras que permiten la toma de agua desde el punto de origen hacia espacios destinados a su abastecimiento (Peytrequín y Arce, 2016).

Los sistemas de evacuación corresponden al conjunto de estructuras que posibilitan extraer (e. g. drenar o dirigir) aguas de un espacio hacia otro. Usualmente estos sistemas permiten redireccionar las aguas que se encuentran empozadas o saturando ciertos sectores de las aldeas precolombinas (Peytrequín y Arce, 2016). 


\section{LOS SISTEMAS DE CAPTACIÓN}

Estos se pueden subdividir en superficiales y subterráneos. Los sistemas de captación superficiales consisten en el conjunto de estructuras que captan el agua de lluvia, de los arroyos, ríos o acequias para el abastecimiento humano. Estos sistemas están compuestos por:

(1) cajas de agua, las cuales son depresiones artificiales en el terreno que permiten almacenar el agua proveniente de escorrentías superficiales.

(2) canales, son conductos elaborados, abiertos o cerrados (con perfiles constituidos de cantos rodados o lajas), que cortan el flujo de agua para conducirla de un punto hacia otro.

Por su parte, los sistemas de captación subterráneos son el conjunto de estructuras que permiten la captación y canalización del agua del subsuelo, esto para su aprovechamiento. Dichos sistemas están compuestos por:

(1) Galerías de filtración, son estructuras elaboradas con rocas y cubiertas por una capa de piedra instalada en el acuífero subsuperficial o para captación indirecta de aguas superficiales (riachuelos, quebradas, entre otros). Esta estructura capta el agua y la canaliza de manera subterránea o superficial hasta cajas de abastecimiento y/o sedimentación.

(2) Cajas de captación, consisten en una estructura elaborada con mampostería de cantos rodados o piedras de dimensiones medias $^{5}$, estas estructuras tienen una morfología redondeada o rectangular. Dichos arreglos sirven para captar el agua desde el manto acuífero (ojo de agua); en algunas ocasiones el agua es canalizada hasta una caja de sedimentación o trampa de sedimentos; aunque es posible que una sola estructura cumpla con ambas funciones. 


\section{LOS SISTEMAS DE EVACUACIÓN}

Los sistemas de evacuación son estructuras que controlan tanto el agua llovida y los flujos superficiales (escorrentías), como regulan el movimiento del agua que corre a través de quebradas y ríos, entre otros. De tal forma, dichas estructuras se pueden sub-dividir en sistemas de evacuación de aguas superficiales y sistemas de evacuación pluviales.

Los sistemas de evacuación de aguas superficiales refieren a estructuras que se encargan de controlar flujos de agua ya existentes en el paisaje, estas son:

(1) Diques, que son muros elaborados con piedras de río (cantos rodados), construidos para la contención del agua de ríos y quebradas.

(2) Zanjas, son cavidades horizontales ${ }^{6}$ y elaboradas sobre el terreno. Estas permiten dar salida y corriente a las aguas estancadas, además de liberar la humedad de los terrenos. Las zanjas, a diferencia de los canales, no presentan empedrados.

Los sistemas de evacuación pluviales posibilitan la extracción y conducción de las aguas de lluvia. Estas estructuras, a la vez, se clasifican en:

(1) Empedrados o pavimentos artificiales, conformados por piedras y que dan curso a las aguas por medio del aprovechamiento de la topografía.

(2) Caños, corresponden a pequeñas zanjas elaboradas con el fin de canalizar el agua de espacios donde se satura y redirigirla a lugares más bajos. Por lo general, los caños no presentan empedrados y tienen dimensiones pequeñas. 
(3) Sumideros, estructuras elaboradas con cantos rodados que permiten la evacuación subterránea de las aguas en determinados puntos; estos generalmente se ubican en zonas topográficas bajas; su morfología corresponde a oquedades a nivel de superficie recubiertas en sus paredes por piedras de río. La base de los sumideros no presenta empedrado alguno, ya que es allí por donde se reincorpora el agua de lluvia al subsuelo.

\section{LOS PETROGRABADOS EN EL CARIBE DE COSTA RICA}

Los petrograbados, son manifestaciones materiales plasmadas en distintas facetas de rocas por medio del grabado de motivos varios, esto usualmente a través de diferentes técnicas como la acanaladura, bajo relieve, alto relieve. Los petrograbados, a nivel general, tenían como propósito la expresión social y materialización de ideas y pensamientos.

En el Caribe costarricense el estudio de los petrograbados se ha efectuado de manera inconsistente. Las investigaciones acerca de este tipo de cultura material se han enfocado en: (1) los estudios estilísticos, (2) el análisis de los diseños buscando su simbología y (3) la asociación temporal (Hurtado de Mendoza y Naranjo, 2018:13,16).

De la misma forma en la base de datos Orígenes (Museo Nacional de Costa Rica, 2019), para la Subregión Caribe Central hay registrados ciento once sitios arqueológicos con presencia de grabados en rocas. Acerca de toda esta información solo existen diez publicaciones (Kennedy, 1970; Snarskis, Crump y Murillo, 1975; Acuña, 1985; Hurtado de Mendoza y Gómez, 1985; Hurtado de 
Mendoza, Gómez y Acuña, 1985; Fonseca y Acuña, 1986; Hernández y Vindas, 2003; Arias, Castrillo y Herrera, 2012; Herrera y Arias, 2016 y Hurtado de Mendoza y Naranjo, 2018), en las cuales se aborda de forma explícita el estudio de este tipo de cultura material. El resto de reportes relacionados a los petrograbados corresponden a referencias propias de informes de investigación arqueológica que no tenían como objetivo el estudio y análisis central de dichas manifestaciones pétreas.

Tal cual fue apuntado, la mayoría de los abordajes en esta materia se han concentrado en la descripción de los motivos presentes. No obstante, es exigua la muestra de trabajos que intentan vincular los motivos de los petrograbados con aspectos funcionales específicos y, mucho menos, donde se relacionen-de forma directa- su ubicación o el vínculo de las representaciones con arquitectura precolombina.

Un ejemplo en esta línea sería el trabajo efectuado recientemente en el sitio Anita Grande, donde se documentaron dos petrograbados que conforman parte de la calzada Parasal (camino precolombino). Estos están ubicados en la línea central del pavimento (hecho con cantos de río) y presentan diseños abstractos. Uno de ellos con motivos de líneas superpuestas y el otro con un diseño cuadrangular de "bastones" o volutas que encuadran un motivo circular. Los autores mencionan que una posible función de los mismos sería indicar la distancia a recorrer a través de esta vía terrestre (Vázquez y Rosenswig, 2019: 49-52).

Otro ejemplo de varios petrograbados dispuestos en las rocas que integran vías precolombinas es el de los caminos empedrados perimetrales de la plaza mayor del Monumento Nacional Guayabo. Allí se identificó en la calzada noreste un petrograbado con diseño meándrico dispuesto boca abajo. Mientras que en la calzada suroeste se documentaron cuatro petrograbados, dos de ellos con diseños meándricos y oquedades, 
uno con dos oquedades y el restante con diseños meándricos y una espiral (Castillo, et al, 2014: 84 y 121-127).

Es importante recordar que los autores de estas líneas retomaron la propuesta de Dubón, Solís y Fonseca (1984) sobre la relación entre la evacuación de agua pluvial con los caminos empedrados del sitio Guayabo de Turrialba (Peytrequín y Arce, 2016).

La bibliografía analizada sobre petrograbados en el Caribe de Costa Rica no revela mayor sustento en cuanto al posible significado o función de los motivos meándricos y de espirales grabados en piedra (e. g. Herrera y Arias, 2016: 192-193). Lo anterior, con la excepción de la evidencia hallada por Fonseca y Acuña (1984: 243 y 244), en el sector IV del Monumento Nacional Guayabo, donde se identificaron 5 petrograbados vinculados con obras hidráulicas, 4 de ellos con motivos de espiral. De aquí la importancia de la presente investigación, la cual estudia - de una manera concreta- la relación concomitante entre los diseños de espirales y meandros con arquitectura hidráulica precolombina; utilizando para ello como un caso de estudio controlado los datos recientemente recabados en el sitio Rosa María, y comparando los mismos con la información disponible del primer sitio mencionado. 


\section{EL SITIO ARQUEOLÓGICO ROSA MARÍA (C-29 RM): SUS OBRAS HIDRÁULICAS Y PETROGRABADOS}

Este sitio se encuentra ubicado en el distrito La Suiza, cantón de Turrialba, en la provincia de Cartago y presenta tres sistemas hidráulicos independientes de captación de aguas, aunque interconectados ya que desaguan a la margen derecha del río Pacayitas.

El primer sistema capta el agua superficial y fue reportado por Hernández (2007), conformado este por dos estructuras que recogen las aguas superficiales (acción favorecida por la topografía inclinada) y, luego, canalizan la misma hacia una zanja cerca del río?.

Dicho sistema está compuesto por dos cajas de agua y dos canales subterráneos. La primera estructura presenta una circunferencia de $30 \mathrm{~m}$, tiene forma circular $\mathrm{y}$, como se mencionó, capta el agua por medio de los cambios de topografía; ya que se encuentra a un nivel inferior con respecto al terreno inmediato circundante.

La caja de agua en cuestión podría estar funcionando, además de colector de aguas, como una caja desedimentación.

Según los actuales dueños de la propiedad donde se halla el sitio Rosa María, en medio de la estructura, cuando esta se carga de agua llovida, se filtra el líquido a través de lo que sería un sumidero que estaría ubicado allí en el subsuelo y dentro de la estructura. El líquido empieza a bajar y, al final de este proceso, quedan demarcadas en el espacio interno de la caja ciertas señas como 'cajetas's. Es muy probable que estas marcas sean el resultado del movimiento del agua, filtración del líquido $y$, por tanto, estén relacionadas con ciertas estructuras en piedra que se encuentren formando parte del sistema hidráulico subterráneo propio de la caja en cuestión.

7. En promedio hay 20 metros de diferencia entre el plano de ubicación de las cajas de agua y el punto de desagüe final 


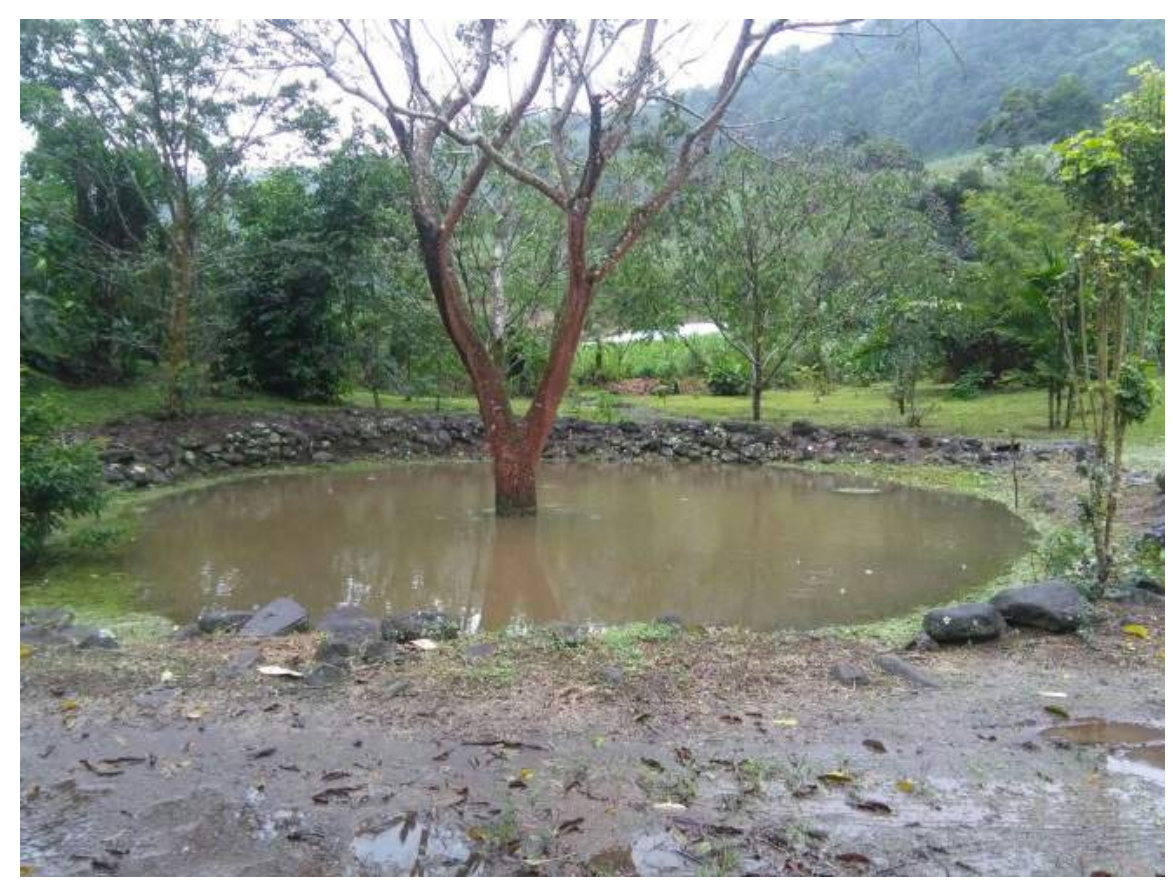

Figura 2. Caja de agua 1, Sitio Rosa María (Foto: Y. Arroyo, 2018).

Además, posiblemente -otra hipótesis de trabajo a contrastar- el agua pasa por medio de un canal subterráneo hasta una segunda caja de agua de menor tamaño y muy alterada por procesos de transformación culturales recientes. De tal forma, las aguas colectadas son dirigidas finalmente por un segundo canal subterráneo que drena las aguas colina abajo.

El segundo sistema de captación en Rosa María fue registrado recientemente por Arce, Aguilar y Peytrequín (2015). Éste consiste en una galería filtrante ubicada sobre una loma que corta las aguas subterráneas. Para lograr esto los ingenieros precolombinos elaboraron una estructura de piedras que permite tomar y dirigir las aguas del sub-suelo superficial. Posterior a dicha toma, el agua 
es conducida a través de una zanja hacia la margen derecha del río Pacayitas; donde se conecta con las aguas ya drenadas del primer sistema.

El tercer sistema, también registrado por Arce, Aguilar y Peytrequín en el año 2015, consiste en la captación de un ojo de agua (o manantial). Esta acción se realiza por medio de una caja de captación elaborada con cantos rodados; la forma de dicha estructura es semicircular y presenta en la pared en donde se capta el agua y las dos paredes laterales tres hileras de piedras superpuestas. En la pared restante por donde se ubica la salida del agua se presentan dos hileras. Es importante resaltar que, como parte de esta caja de captación, se halló un petrograbado con motivo de espiral, del cual se discutirá más adelante.

Una vez que el agua abandona esta caja de captación es canalizada por medio de una zanja hasta encontrarse con las aguas drenadas de los dos primeros sistemas.

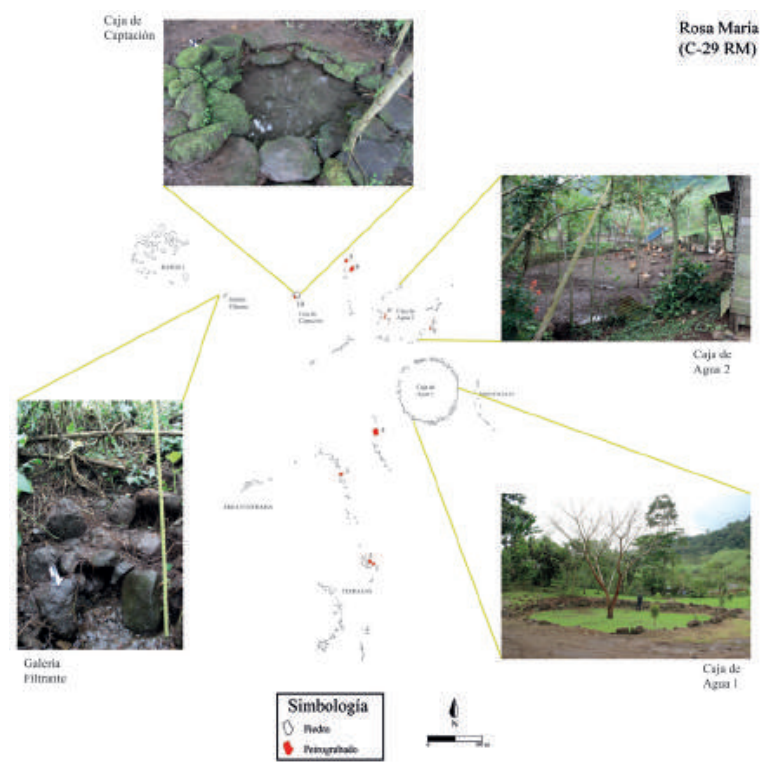

Figura 3. Croquis del sitio Rosa María, con detalle de obras hidráulicas 


\section{LOS PETROGRABADOS DE ROSA MARÍA}

Dentro de los elementos culturales relacionados con las estructuras hidráulicas de este sitio arqueológico (vistas como un conjunto integrado) podemos mencionar diez petrograbados aún in situ (más otros tres removidos).

A nivel general, y relacionado a aspectos de clasificación formal de los diseños vistos, podemos mencionar que existen dos motivos generales que dominan en los petrograbados del sitio Rosa María: los diseños meándricos y las espirales. Si bien esto es una simple clasificación formal, ya trae consigo aspectos interpretativos de inicio que relacionamos con las estructuras hidráulicas y su función dentro del sitio.

Los motivos meándricos, asociados con los meandros propios de diferentes cuerpos de agua como ríos o riachuelos, y las espirales que aparecen en Rosa María, las asociamos en términos generales con el agua (luego del cruce de variables nos hizo ser más precisos en la interpretación).

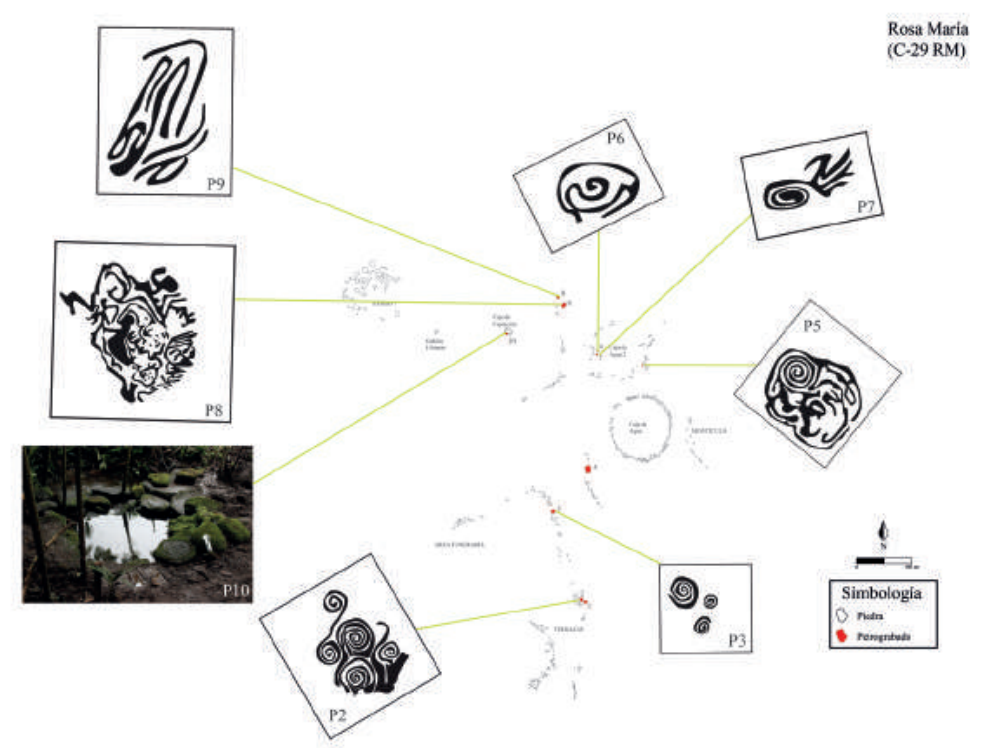

Figura 4. Croquis del sitio Rosa María, con detalle de ubicación de petrograbados 
De forma que, lo que presentaremos a continuación trata de entrelazar -inicialmente- informaciones respectivas a los motivos vistos en los petrograbados junto a su ubicación dentro del sitio Rosa María, así como su orientación general, y si esto establece otras relaciones entre grabados particulares y estructuras hidráulicas específicas. No está demás decir que este ejercicio nunca se ha hecho en la arqueología costarricense.

Ahora bien, relacionados a la primera caja de agua hallamos cinco petrograbados que se ubican al Oeste, Suroeste y Noreste de esta primera estructura circular. Acá resaltan algunos aspectos importantes: (1) la presencia de motivos de espirales y; (2) la asociación de "cara a cara" entre algunos de los petrograbados y la caja de agua, aspecto que no consideramos menor.

Esta última relación señalada se acentúa gracias a dos aspectos concretos del paisaje construido: la orientación de los diseños y la altura de los $\operatorname{litos}^{9}$ en los cuales se colocaron dichos motivos. De tal forma, concentrados al Suroeste del eje central de la caja se hallan 4 petrograbados, en una especie de terrazas sobre el terreno propio donde se ubica la estructura hidráulica (estas terrazas en un plano de visión más alto que la obra hidráulica).

En la primera terraza se encuentra un petrograbado (P4), el más grande del sitio (de acuerdo a sus dimensiones) y el más cercano a dicha estructura. El motivo tallado corresponde con líneas meándricas, lamentablemente el diseño del mismo está prácticamente perdido; lo anterior debido a la meteorización ${ }^{10}$ de la roca.

En la segunda terraza se da una especie de concentración de petrograbados (tres especímenes), unos con motivos másabstractos que otros. Destaca aquí la presencia en dos petrograbados de tres o más espirales en la conformación de sus diseños (P2 y P3) pero, sobre todo, el hecho de que el petrograbado registrado como P3 
guarda una relación Inter visual (inter-visualización, sensu Criado, 1999) con la primera caja de agua. De nuevo, no pensamos que esto sea azaroso.

Sumado a lo anterior, hicimos el ejercicio de registrar en qué momento del día los motivos tallados en los petrograbados eran más claros y observables desde la caja de agua. Así, este petrograbado (el P3) se hace observable -desde la caja de aguaen las primeras horas del día (aspecto que no ocurre a medio día ni al atardecer). Su ubicación planificada en el espacio así lo permite: localizado en un plano superior y recibiendo -sin obstáculos aparentes- los primeros rayos del sol.

A lo anterior habría que sumarle el impacto visual de, en ciertos momentos, tener la caja cargada con agua y ver la luz solar reflejada en la misma. ${ }^{11}$

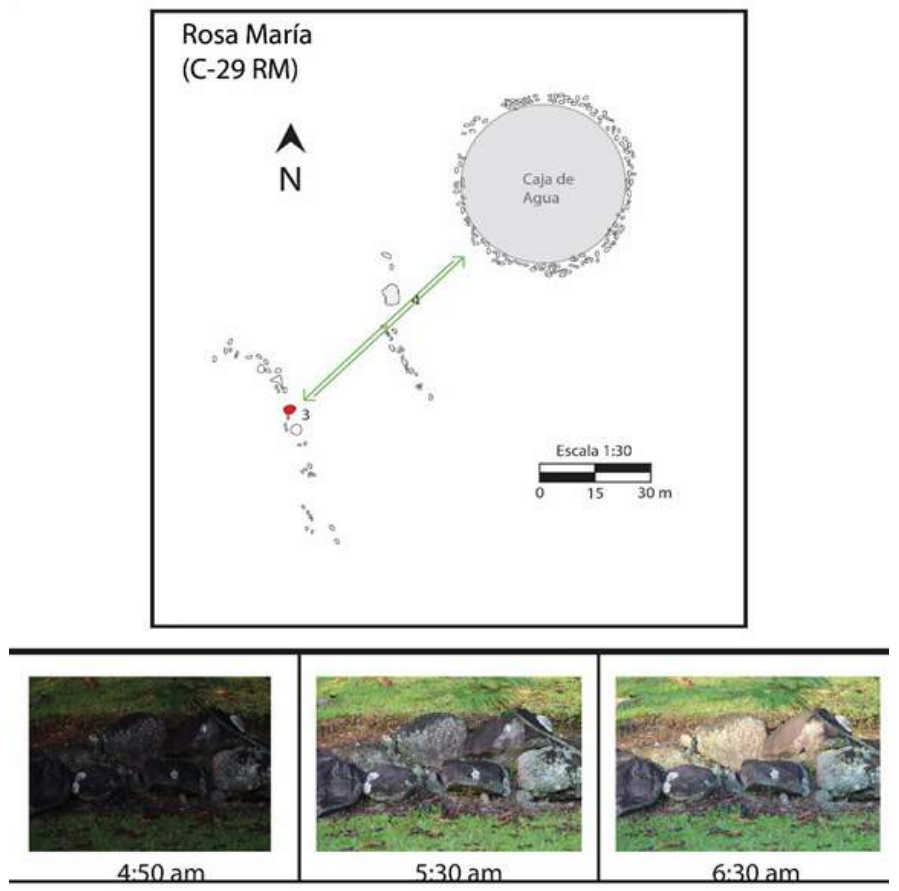

Figura 5. Esquema de relación cara con cara, entre caja de agua 1 y P3, sitio Rosa María (Foto: M. Arce, 2016).

11. Los autores son testigos directos de la ocurrencia de este fenómeno, pudiendo observar completamente llena de agua dicha obra hidráulica. 
Por su parte, en medio de las dos cajas de agua (separadas por una distancia de 5.65 metros entre una y otra) se encuentra otro petrograbado (el P5). Este presenta -a la vez- motivos de meandro y espirales en una de sus caras.

Con este ejemplo concreto es posible ir dilucidando la interpretación de los dos motivos presentes y dominantes en los grabados del sitio Rosa María (los meandros y las espirales), la cual se irá reforzando a lo largo de este escrito con los datos recuperados.

Quizá, aquí el meandro de P5 esté aludiendo a la conducción del agua que sale de una estructura hidráulica (segunda caja de agua) y su canalización, por medio de un canal subterráneo que se extiende por más de 7 metros aproximadamente, para luego -quizá- descender mediante una zanja o por la misma acción de la gravedad hasta desembocar en el río Pacayitas; mientras la espiral (al mismo tiempo y con relación a la segunda caja de agua) indicaría la contención controlada del líquido.

Con respecto a lo anterior, valga decir que la roca donde se halla P5 tiene una orientación Noreste, y su espiral cierra hacia el Oeste; precisamente la dirección en donde se ubica la segunda caja de agua.

Dicha caja de agua se encuentra en un estado muy alterado por procesos de transformación cultural. ${ }^{12}$ No obstante, la información apunta a que la entrada de líquido en la segunda caja estaría en un sector de su eje Sureste; coincidente con la "indicación" del flujo dictada por la espiral grabada en P5.

Como parte de las piedras removidas dentro de la segunda caja de agua, hay dos que cuentan con petrograbados (P6 y P7). A diferencia de los anteriores, los soportes líticos en los que están estos diseños son de dimensiones mucho más reducidas, 
pudiendo ser estos petrograbados de carácter móvil. No obstante, el tamaño y material de las piedras es análogo al resto de litos que se utilizaron para construir el perímetro empedrado de la segunda caja. Por tanto, consideramos que las mismas formaban parte de las piedras que constituían la estructura en sí.

Ambos petrograbados (P6 y P7) presentan espirales. Es importante aclarar que existe una gran probabilidad de que las piedras con grabados hayan sido movilizadas de su ubicación original (esto por su tamaño y poco peso). Sin embargo, pensando en la posibilidad futura de una restauración de esta obra, habría que considerar -a partir de los datos recuperados en asocio a las otras estructuras y su relación con los petrograbados- que ambas espirales podrían orientar su cierre hacia el Noroeste; precisamente el sector donde el líquido abandona la segunda caja e ingresa en el canal ya mencionado.

Por otra parte, el petrograbado 8 (P8) se ubica al costado Noroeste de la segunda caja de agua (fuera de esta última). Es significativo que el eje de orientación de la roca es Norte-Sur, igual que otros petrograbados de allí (e. g. P2 y el P5 ya discutidos).

Sin embargo, las representaciones en P8 son muy complejas y abstractas (de tipo "laberíntico") como para aventurar una interpretación del conjunto de estas. Lo que sí podemos apuntar aquí son dos aspectos: (1) en parte de la faceta inferior el grabado exhibe motivos meándricos, orientados en un eje Sureste-Noroeste, lo que podría estar indicando la orientación del canal subterráneo. ${ }^{13}$ (2) En vínculo directo con lo anterior, consideramos que no es casual que P8 se halle al borde de una terraza en donde hay una inclinación abrupta del terreno hacia el Oeste. Ello no solo estaría marcándole (a modo de prevención) a los transeúntes del sitio el desnivel agudo del terreno y la localización de un espacio menos estable para su tránsito; sino, también interpretamos que el P8 sería un medio para que los 
ingenieros precolombinos conociesen la posible localización y orientación del canal subterráneo, esto en caso de necesitar repararlo por alguna razón (saturación, bloqueo, etc.).

Cerca de P8 se halló el P9 el cual, en consonancia con la idea que recién se expuso, exhibe motivos de meandro. De nuevo, consideramos que esto apelaría al canal subterráneo ya que se encuentra cerca de su desembocadura y que dirige el agua colina abajo hacia el punto de desagüe cerca del río Pacayitas.

El último petrograbado (P10) con forma de espiral y ubicado en la caja de captación del tercer sistema, está dispuesto y orientado, precisamente su abertura final, en relación exacta y en dirección a la entrada del agua a esta obra hidráulica. Pauta constructiva y simbólica que es consistente en este sitio con otras estructuras hidráulicas.

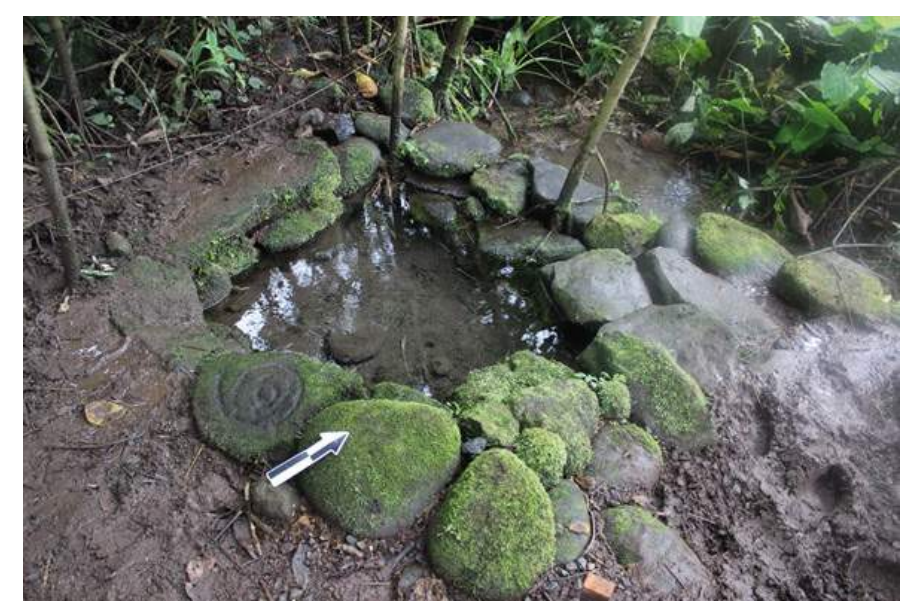

Figura 6. Caja de Captación, Sitio Rosa María (Foto: M. Arce, 2015). 


\section{EL MONUMENTO NACIONAL GUAYABO: SUS OBRAS HIDRÁULICAS Y PETROGRABADOS}

El sitio arqueológico Guayabo de Turrialba posee la mayor complejidad en cuanto a los conjuntos hidráulicos conocidos para los sitios arqueológicos del Caribe, de ahí el bien merecido nombramiento como patrimonio mundial de la ingeniería recibido en el 2009. Así, podemos encontrar en solo este sitio sistemas de captación de agua, evacuación de flujos superficiales y evacuación de aguas pluviales.

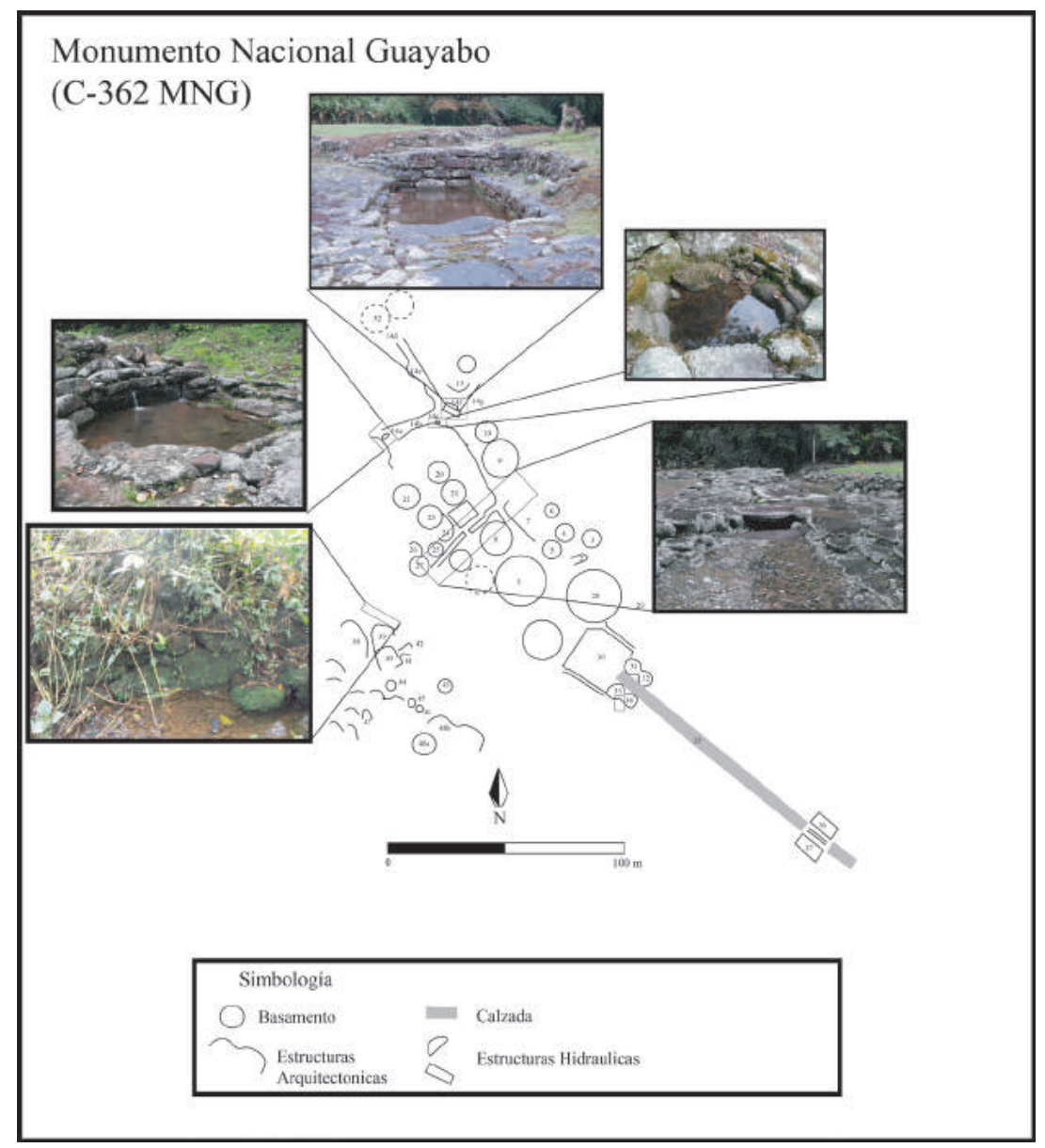

Figura 7. Croquis del Monumento Nacional Guayabo, con detalle de obras hidráulicas. 
El primer sistema de captación, ubicado en el conjunto 2 del sector IV ${ }^{14}$ (Arroyo y Arce, 2018), se encuentra conformado por dos tomas de agua ubicadas al pie del "Cerro del Tigre" y en puntos geográficos distintos, aunque parece ser que ambos provienen del mismo acuífero (Dubón, Solís y Fonseca, 1984).

En la primera de las tomas, el agua es sustraída desde el subsuelo por medio de una caja de captación (14a), análoga a la presente en el sitio Rosa María, de forma semicircular; misma construida por rocas angulares y cantos rodados. En la pared Oeste donde brota el agua se identificaron tres hileras. La primera de ellas presenta las rocas de mayor tamaño; así como un grabado con motivo de espiral que, al igual que en la caja de captación de Rosa María, está dispuesto y orientado en dirección a la entrada del agua a esta obra hidráulica.

En el caso de las paredes al Norte y al Sur las tres hileras se presentan de manera escalonada, permitiendo el acceso hacia el interior de la estructura. Finalmente, en la pared Este, conformada por dos hileras, es posible observar el punto por donde se vierte el agua hacia un canal subterráneo (14b); este último construido con piedras planas (lajas) que conforman su suelo y tapa, mientras las paredes laterales se erigieron con cantos rodados. Este canal dirige el agua hasta una caja de sedimentación y suministro (14f).

En la segunda de las tomas el agua se capta por medio de una galería filtrante (14d), estructura cavada directamente en la tierra (elaborada en este caso sin rocas) que permite la adquisición del líquido desde un acuífero sub-superficial. El agua es canalizada desde este punto por un canal abierto hasta tres aberturas ubicadas a la orilla de un empedrado. Debajo de este se construyó un canal subterráneo (14e) que conecta estos tres puntos con la caja de sedimentación y suministro (14f). 
Esta caja de sedimentación y suministro (14f) se convierte en el punto de encuentro de las dos tomas de agua. Dicha estructura cuadrangular presenta, al igual que se da en la caja de captación de este mismo sitio (14a), el ingreso del líquido por su pared Oeste. Aunque en este caso en dos puntos, posiblemente uno respondiendo a cada una de las tomas de agua (Arroyo y Arce, 2018).

Asimismo, en la pared Este se observa -en concordancia con la morfología y orientación de la caja en sí- la salida del agua de la estructura hacia un canal de desfogue $(14 \mathrm{~g})$, este cubierto por tres lajas de gran tamaño. De ahí el agua es reintegrada al río Lajas a través de un canal superficial que presenta varios diques, ello a modo de difusores (Arroyo, 2016), cuya función es evitar la erosión de las plataformas monticulares que soportaron las estructuras habitacionales cercanas.

El segundo sistema de captación de Guayabo toma flujos superficiales provenientes de la quebrada Chanchera y los encauza por un canal superficial hasta reintegrarlos en la cuenca del río Lajas. Dentro de las estructuras que componen este conjunto resalta la presencia de un puente hecho de lajas y algunas escaleras de acceso al lecho del canal.

En cuanto a los sistemas de evacuación de aguas, en Guayabo se ubicaron diques en la quebrada Chanchera para mitigar la erosión de los montículos sobre los que se dispusieron las estructuras habitacionales; esto muy similar a otro caso visto en la misma región, en el sitio Agua Caliente de Cartago (Peytrequín, 2009).

El Monumento Nacional Guayabo es el sitio donde mejor se aprecian los sistemas de evacuación de aguas pluviales. En ese sentido, destacan los empedrados (calzadas) para impermeabilizar el suelo y evitar la anegación de la superficie transitada/ habitada. 
Por su parte, el uso de caños para canalizar las aguas que fluyen por los empedrados es evidente en espacios como las estructuras llamadas "31-32" y "33-34", asimismo; cabe subrayar la existencia de sumideros cerca del sistema de captación subterránea para separar, posiblemente, las aguas pluviales de las subterráneas. Por último, al norte del montículo "3334 " de Guayabo se observa otro sumidero que drena las aguas provenientes de la calzada noreste de la plaza mayor (Ver figura 7).

\section{LOS PETROGRABADOS DEL SECTOR IV DEL MONUMENTO NACIONAL GUAYABO}

En el Monumento Nacional Guayabo se registran más de cuarenta petrograbados; sin embargo, son de especial interés para esta investigación los que se emplazan en el sector conocido como IV, ello debido al tipo de motivos representados en las rocas y su vínculo espacial con las obras hidráulicas.

Fonseca y Acuña (1984) mencionan la presencia de cuatro petrograbados en este sector, a los cuales debemos sumar uno reportado en 1984 en un informe del Trabajo Comunal Universitario (Rojas, Chávez, Guerra y Moinieri, 1984) y otro petrograbados más, ubicado directamente en la caja de captación (14a).

De los seis petrograbados contabilizadas en el sector IV, cinco de ellos comparten el motivo de la espiral; lo cual no es un dato casual, tres de estos identificados por Fonseca y Acuña (los denominados"11"15,"33"y"34") están dispuestos en el empedrado (14e), debajo del cual discurren las aguas por medio de un canal subterráneo que provienen de la galería filtrante (14d); ubicados cerca de la caja de sedimentación y suministro (14f) (Fonseca y Acuña, 1984). 
Los dos petrograbados restantes corresponden, primero, con una espiral grabada sobre una roca que formó parte de un basamento doble y acinturado (estructura 52). Lamentablemente este objeto fue removido, aunque hoy día es posible observar el espacio que ocupaba en dicha estructura (Arroyo, 2017). Por su parte, el segundo petrograbado con motivo de espiral, se encuentra tallado en una de las piedras que forman la pared Oeste de la caja de captación (14a); misma por donde ingresa el líquido a esta estructura.

El petrograbado 23, descrito por Fonseca y Acuña (1986) para Guayabo, presenta una oquedad que sugiere un uso más práctico o utilitario. Este motivo se encuentra acompañado de otras once oquedades de pequeñas dimensiones, dos de las cuales están conectadas con líneas. Dicho petrograbado, ubicado sobre el empedrado (14e), parece encontrarse en relación directa con los fogones identificados en el conjunto 1 del sector IV de este sitio (Arroyo y Arce, 2018).

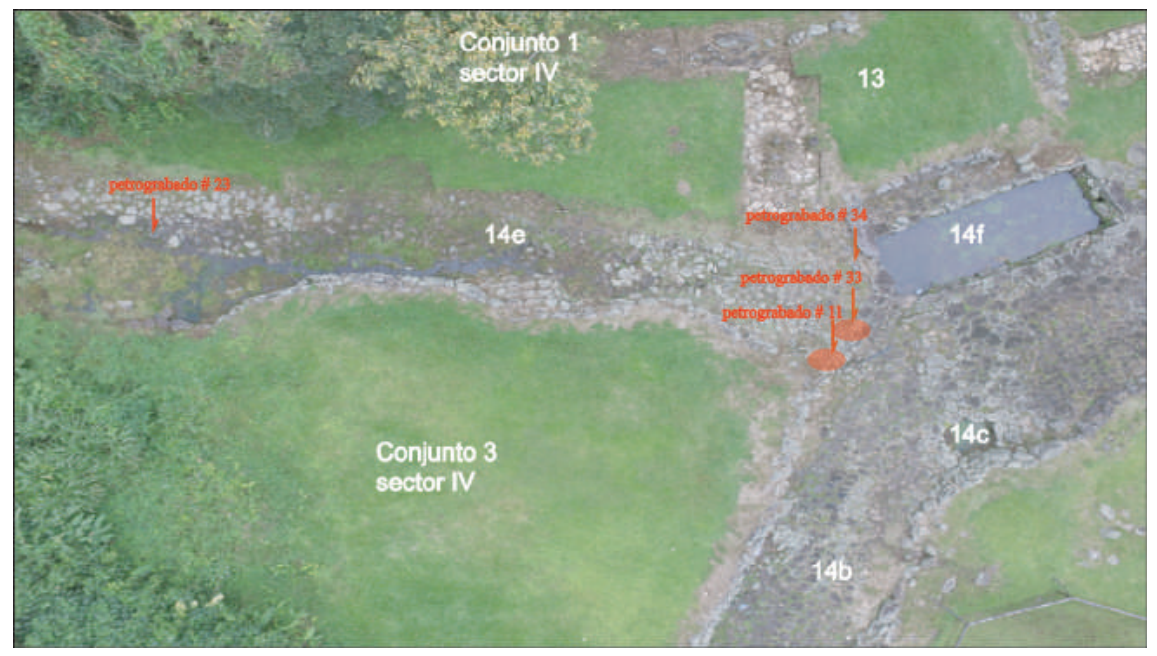

Figura 8. Ubicación de petrograbados registrados por Fonseca y Acuña (1986), Monumento Nacional Guayabo. (Foto: M. Arce, 2018). 
Finalmente, cabe resaltar un petrograbado registrado en el sitio Guayabo (Arroyo, 2017) y dispuesto en las proximidades de una quebrada sin nombre al este del sitio, en lo que la autora describe como un sistema de difusores de velocidad de agua. Dicho petrograbado presenta motivos meándricos. No deja de llamar la atención la asociación entre estos grabados y distintos sistemas de evacuación de agua, en este caso el acomodo cultural de diferentes conjuntos de rocas (en medio de la propia quebrada) que producen una disminución en la aceleración del agua que va dirigida hacia el río Lajas; de nuevo, esto como una medida preventiva para evitar la erosión del terreno donde se ubica el núcleo arquitectónico del sitio.

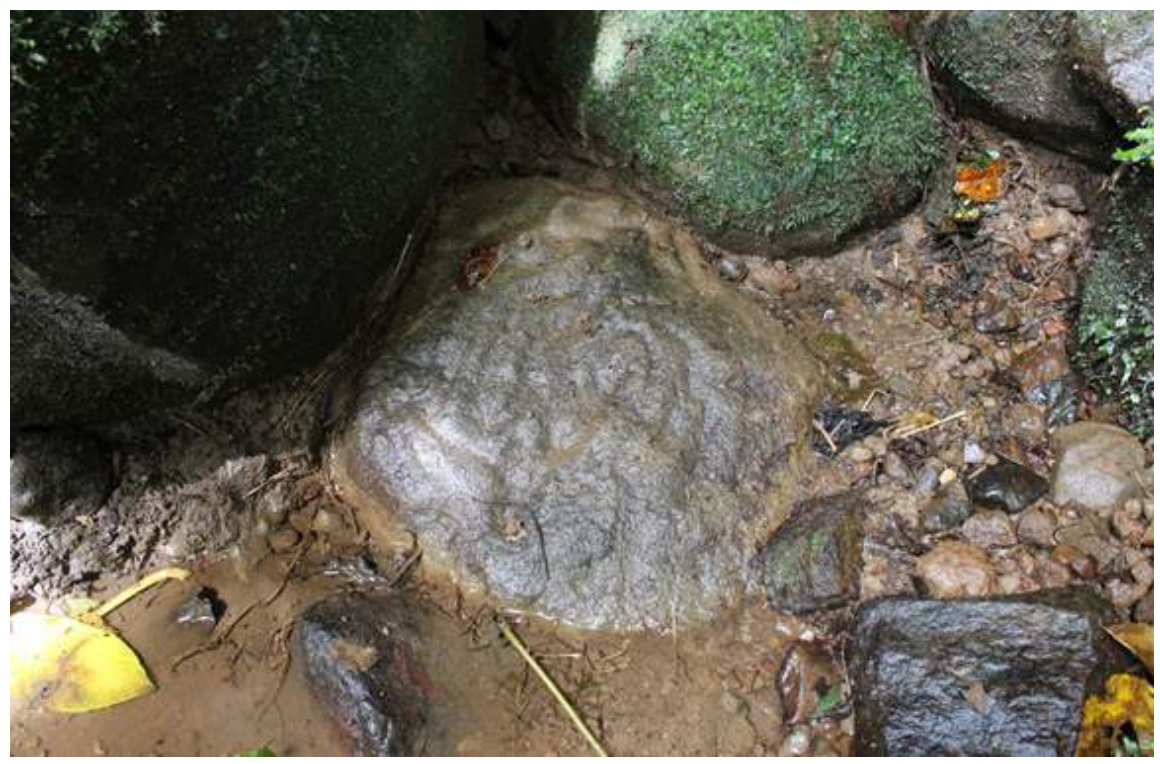

Figura 9. Petrograbado con diseño de meandro, registrado por Gabriela Arroyo, Monumento Nacional Guayabo (Foto: M. Arce, 2017). 


\section{CONCLUSIONES}

Esta investigación buscó aclarar el panorama acerca de las particularidades ligadas a las obras hidráulicas precolombinas del Caribe costarricense y los petrograbados con motivos de espirales (con características específicas) y meandros, los cuales constituyen parte de las propias estructuras en cuestión.

Se aclara que no son todas las estructuras hidráulicas del Caribe costarricense (abordadas dentro del esquema de clasificación señalado al principio de este artículo), las que están vinculadas a espirales y meandros grabados en piedra.

Al respecto, esta asociación la encontramos patente en dos tipos de obras de este calibre. Por un lado, las cajas de agua (en el sitio Rosa María) y, por el otro, las cajas de captación y suministro (para los sitios Rosa María y el Monumento Nacional Guayabo).

En el caso de la segunda clase de estructuras, podemos vislumbrar otros ámbitos de relación concomitante, en específico: la orientación del final- salida del motivo de la espiral; la cual coincide con la ubicación exacta de la entrada del agua a las cajas de captación y suministro en ambos sitios arqueológicos analizados (ver figura 5).

En el caso del motivo del meandro, este puede estar aludiendo a la conducción del agua que sale de una estructura hidráulica y discurre hacia flujos de agua naturales. En el sitio Rosa María esto se puede notar claramente en los petrograbados 5, 8 y 9 y su relación con el río Pacayitas; mientras en el Monumento Nacional Guayabo hay un vínculo entre este motivo presente en el petrograbado registrado en las inmediaciones de la quebrada Lajitas. 
En suma, se encontraron las siguientes asociaciones:

1- Petrograbados con motivos de espiral y el ingreso/egreso del agua en ciertas estructuras hidráulicas (cajas de captación y cajas de suministro) y

2- Petrograbados con motivos meándricos vinculados a espacios asociados con la evacuación cultural del agua (sistemas de evacuación de aguas) hacia ríos y quebradas permanentes.

Los postulados antes mencionados se presentan en más de un sitio y no de manera aislada; lo cual podría estar indicando una característica a nivel regional acerca del fenómeno de la gestión del agua en la antigüedad y dentro del territorio costarricense.

Más allá de apelar a arquetipos universales o a múltiples acepciones sin decantarse por alguna en particular, lo cual no nos llevan a ninguna explicación plausible, a través de este trabajo hemos realizado un acercamiento contextual de los motivos de espirales y meandros, asociándolos a obras hidráulicas específicas. Lo anterior con base en la correlación de datos concretos y evidencia corroborable en los sitios arqueológicos Rosa María (C29 RM) y en el Monumento Nacional Guayabo (C-365 MNG) del Caribe de Costa Rica. 


\section{AGRADECIMIENTOS}

Le agradecemos a la familia Araya Jiménez, en especial a Don Vianey, Doña Ligia, Don Fabián y Yoset, esto por la oportunidad de investigar en el sitio arqueológico Rosa María y su siempre anuencia a conocer más sobre el pasado precolombino de Costa Rica. Su hospitalidad es y sigue siendo ejemplar. A ellos reconocemos, además, su interés constante por la conservación y divulgación del patrimonio arqueológico. 


\section{BIBLIOGRAFÍA}

Acuña, V. (1985). Un Petroglifo de la cuenca media del Reventazón Costa Rica: su análisis. Vínculos 11 (1-2). Museo Nacional, págs. 4756.

Arce, M., aguilar, M. y J. Peytrequín. (2015). Sitio Rosa María (C-29RM): Nuevos datos acerca de sus obras hidráulicas. Informe inédito en la biblioteca de los autores. San José, Costa Rica.

Arias, A.C., Castrillo, B y G. Herrera (2012). Una historia escrita en piedra. Petrograbados de Guayabo de Turrialba. San José. Vicerrectoría de Acción Social, Universidad de Costa Rica.

Arroyo, G. (2016). Configuración del acceso noreste a la aldea precolombina Guayabo de Turrialba (C- 362 MNG). Diseño arquitectónico, cronología constructiva y potencial de conservación de la evidencia sobre costumbres alimenticias (219-B5-079). Informe de investigación. Manuscrito, Escuela de Antropología, Universidad de Costa Rica. San José, Costa Rica.

Arroyo, G. (2017). Configuración del acceso noreste a la aldea precolombina Guayabo de Turrialba (C- 362 MNG). Diseño arquitectónico, cronología constructiva y potencial de conservación de la evidencia sobre costumbres alimenticias (219-B5-079). Informe de investigación. Manuscrito, Escuela de Antropología, Universidad de Costa Rica. San José, Costa Rica.

Arroyo, G. y Arce, M. (2018). Sitio Arqueológico Guayabo: nuevos aportes para el análisis del sector norte del núcleo arquitectónico. Ponencia presentada en el simposio 50 años de fundación del laboratorio de arqueología de la Universidad de Costa Rica. San José, Costa Rica. 
Castillo, L.; Barrascout, E.; Arce, M.; Castillo. M. Y Ramírez, J. (2014). "Proyecto de restauración y conservación de estructuras arquitectónicas del Monumento Nacional Guayabo (Sector Calzada Caragra (rasgo $\mathrm{N}^{\circ} 35$ ), Montículos en forma de 8 (rasgos $\mathrm{N}^{\circ}$ 31-32 y 33-34) y Plaza Mayor (rasgo N³0))". Informe de evaluación arqueológica. Manuscrito, Nuevo Espacios, Desarrolladores Vascos, Sistema Nacional de Áreas de Conservación, Licitación Abreviada 2012-LA-000-311-01100 y ampliación. San José, Costa Rica.

Criado, F. (1999) Del terreno al espacio: planteamientos y perspectivas para la arqueología del paisaje. Compostela, España, Universidad de Santiago de Compostela.

Diccionario de la Real Academia Española. (2016). Consultado el 20 de enero 2016 en http://lema.rae.es/drae/

Dubón, J.; Solís, H. y O. Fonseca. (1984) Arqueología e ingeniería hidráulica en Guayabo de Turrialba. Informe del Primer Seminario Nacional de Ingeniería de los Recursos Hidráulicos. (San José, 18, 19 y 20 octubre 1984). San José, Universidad de Costa Rica, sin paginar.

Fonseca, O. (1979) Informe de la primera temporada de reexcavación de Guayabo de Turrialba. Vínculos 5 (1-2). Museo Nacional, págs. 35-52.

Fonseca, O. y Acuña, V. (1986) "Los Petroglifos de Guayabo de Turrialba y su contexto". en LANGE, F Y NORR, L., eds., Prehistoric settlement patterns in Costa Rica. Journal of the Steward Anthropological Society (1982-1983) 14 (1-2), Illinois, Urbana, págs. 237-354. 
Hernández, C. (2007). Hallazgo de un acueducto precolombino en la cuenca media del río Pacuare, Costa Rica. Cuadernos de Antropología 17-18. Universidad de Costa Rica, págs. 165-176.

Hernández, M. y Vindas, F. (2003). El petroglifo Unión, sitio arqueológico salitrillo (C-119-Si). La Unión de Cartago. en ARIAS, A.C., BOZZOLI, M.E., CHANG, G., ROJAS, M. comps., Segundo Congreso sobre Pueblos Indígenas., Universidad de Costa Rica. Costa Rica, San José, págs. 111-117.

Herrera, G. y A.C. Arias (2016). Los petrograbados de Guayabo de Turrialba, Costa Rica: Un acercamiento a su significado. Herencia 29 (2). Universidad de Costa Rica, págs. 175-204.

Hurtado De Mendoza, L. Y Gómez, J. (1985) Breve descripción comparativa de dos regiones arqueológicas en Costa Rica: Guayabo de Turrialba y Ta 'Lari de Pacuare. Vínculos 11 (1-2). Museo Nacional, págs. 67-100.

Hurtado De Mendoza, L., Gómez, L. y Acuña, V. (1985) Petroglifos de Guayabo: Clasificación y relaciones deposicionales. Revista de Ciencias Sociales volumen especial. Universidad de Costa Rica, págs. 87-90.

Hurtado De Mendoza, L. y Naranjo, D. (2018). “Taxonomía y datación de petroglifos en la cuenca media del Reventazón, Costa Rica", en Hurtado De Mendoza, L., coord., Arqueología del Caribe Costarricense. Contribuciones Científicas, Vol. 2., Centro de Información para el Desarrollo (CID), Master Litho S.A. Costa Rica, San José, págs. 13-39. 
Instituto Metereológico Nacional. Sitio web. (2016) Consultado el 20 de enero 2016 en http://www.imn.ac.cr.

Kennedy, W. (1970). Petroglifos en la cuenca del drenaje del río Reventazón, Costa Rica. Revista del Instituto Geográfico Nacional, julio-diciembre, págs. 49-97.

Museo Nacional de Costa Rica. (2019). Base de datos Orígenes. Consultada el 20 de junio de 2016 en http://origenes. museocostarica.go.cr/busquedaGeneral.aspx

Peytrequín, J. (2009). Agua Caliente, espacialidad y arquitectura en una comunidad nucleada antigua de Costa Rica. Cuadernos de Antropología 19. Universidad de Costa Rica, págs. 31-55.

Peytrequín, J. y Arce, M. (2016). "Obras hidráulicas antiguas del Centro y el Caribe costarricense (600-1200 d.C.). Una propuesta formal de clasificación", en Hurtado De Mendoza, L., coord., Arqueología del Caribe Costarricense. Contribuciones Científicas Vol. 1., Editorial e Imprenta LIL, San José, Costa Rica, págs. 67-86.

Rojas, R., Chavez, A., Guerra, E. y Moinieri, O. (1984). Informe semanal del TCU (30 de enero al 4 de febrero de 1984). Informe de investigación. Manuscrito Inédito, Escuela de Antropología, Universidad de Costa Rica. San José, Costa Rica.

Snarski, M., Crump, M. y Murillo, C. (1975) Análisis de un Petroglifo del Valle de Turrialba, Costa Rica. Vínculos 1 (2). Museo Nacional, págs. 83-91. 
Vázquez, R. (2006) Planimetrías de varios sitios arqueológicos con arquitectura y obras viales de la zona de Línea Vieja, Caribe Central de Costa Rica. Proyecto Caminos y sitios monumentales: Conocimiento ambiental y alta ingeniería en las sociedades precolombinas del territorio de Costa Rica. Informe de investigación. Manuscrito, Departamento de Antropología e Historia, Museo Nacional, Costa Rica.

Vázquez, R. y Rosenswig, R. (2019). Desarrollo y alcances del poder cacical amerindio en el Caribe Central de Costa Rica: Los sitios Las Mercedes-1 y Anita Grande (Temporada 2018). Informe Arqueología DAH-2018-067. Manuscrito, Departamento de Antropología e Historia, Museo Nacional, Costa Rica. 